width of rib in the two groups. The results indicate that disturbances in the formation of cartilage seen by others are not longstanding enough or severe enough to cause a measurable reduction in the mineral content of ribs in a study of this size. Reduced mineral content in ribs of infants dying of chronic illnesses was expected as studies in the neonates have shown that undernutrition (relative to the nutrition provided by the placenta when it is functioning correctly) may result in pronounced reductions in the mineral content of bone. ${ }^{4}$

A Horsman and $\mathrm{J}$ Truscott were employed by the Medical Research Council and supported by an External Scientific Staff grant, and S Ryan was supported by a grant from the Special Trustees of the General Infirmary, Leeds.

\section{References}

1 Peterson DR, Benson EA, Fisher LD, Chinn MN, Beckwith JB. Post natal growth and the sudden infant death syndrome. Am J Epidemiol 1974;99:389-94.

2 Sinclair-Smith C, Dinsdale F, Emery J. Evidence of duration and type of illness in children found unexpectedly dead. Arch Dis Child 1976;51:424-9.

3 James JR, Truscott J, Congdon PJ, Horsman A. Measurement of bone mineral content in the human fetus by photon absorpiometry. Early Hum Dev 1986;13:169-81.

4 James JR, Congdon PJ, Truscott J, Horsman A, Arthur R. Osteopenia of prematurity. Arch Dis Child 1986;61:871-6.

Correspondence to Dr S Ryan, Neonatal Intensive Care Unit, Clarendon Wing, The General Infirmary, Leeds LS2 9NS.

Accepted 10 November 1987

\title{
Functional residual capacity related to hepatic disease
}

\author{
A GREENOUGH, J POOL, C BALL, G MIELI-VERGANI, AND A MOWAT \\ Department of Child Health, King's College Hospital, London
}

SUMMARY Functional residual capacity was measured in 20 children (aged 3.1-11.2 years) with liver disease. Children with severe liver disease, regardless of diagnosis, had reduced functional residual capacities ( $<80 \%$ of expected). Children with $\alpha-1$ antitrypsin deficiency had higher functional residual capacities than those with other hepatic diagnoses. Three children had a functional residual capacity $>120 \%$ of expected, all had $\alpha-1$ antitrypsin deficiency.

In childhood $\alpha-1$ antitrypsin deficiency is usually associated with liver disease, but it has been suggested that asthma and bronchitis may be commoner in children over 8 years of age with $\alpha-1$ antitrypsin deficiency. ${ }^{1}$ No respiratory measurements, however, were performed and the authors were unable to comment whether the symptoms were early manifestations of emphysema. ${ }^{1}$

Recently it has become possible to measure functional residual capacity by helium gas dilution reproducibly and accurately even in children as young as 2 years of age. ${ }^{2}$ The aim of the present study, using this technique,,$^{2}$ was to determine if abnormalities of functional residual capacity were present in young children with $\alpha-1$ antitrypsin deficiency. Secondly, by comparing their results with those of children with other hepatic diagnosis, we aimed to determine whether the abnormalities specifically related to $\alpha-1$ antitrypsin deficiency rather than a non-specific effect of hepatic disease.

\section{Patients and methods}

Twenty children attending the paediatric liver service at King's College Hospital were studied. Only one child, who had previously been diagnosed as suffering from asthma, had respiratory symptoms. Twelve children suffered from $\alpha-1$ antitrypsin deficiency (five boys and seven girls, median age 5 years (range 3.1-11.5 years)). Eight other children were also studied: five with biliary atresia, two who had had neonatal hepatitis, and one with congenital hepatic fibrosis. This latter group, who were designated controls, consisted of three boys and five girls with a median age 4.5 years (range $3.5-8.6$ years). The children in both groups were classified into four subgroups according to disease severity (figure).

Ethical permission for the study was granted by King's College Hospital ethical committee and parental consent was obtained.

All children had their functional residual capacity measured by helium gas dilution using a water sealed spirometer (Gould Pulmonet 3) in the paediatric respiratory laboratory. ${ }^{2}$ All recordings were coded and then analysed blind of the child's clinical details. Each child's results were compared with published normal data ${ }^{2}$ or data collected from 60 healthy children of similar ages to the study population. Functional residual capacity was ex- 


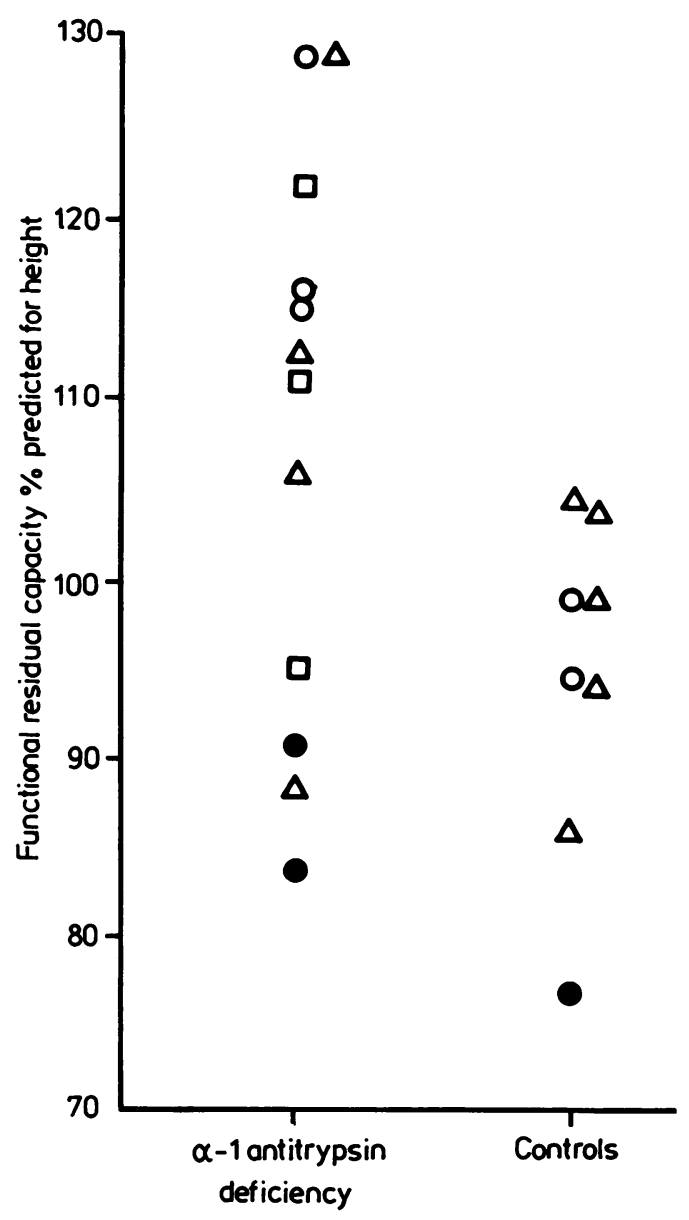

Figure Functional residual capacity is expressed as a percentage of that predicted for height in the children suffering from $\alpha-1$ antitrypsin deficiency (left) and with other hepatic diagnoses (controls) (right). Each child is depicted according to the severity of liver disease: $\mathrm{O}=$ no clinical or biochemical evidence of liver disease at the time of measurement (subgroup 0); $\square=$ mildly abnormal liver function tests but no abnormal clinical signs (subgoup 1); $\triangle=$ abnormal liver function tests, enlarged liver or spleen, or both (subgroup 2); and $=$ cirrhosis (proved on biopsy) with massive splenomegaly with or without ascites (subgroup 3).

pressed as the percentage for height or age using these normal ranges. Children who had a functional residual capacity $\geqslant 120 \%$ of that predicted for height were remeasured 20 minutes after bronchodilator treatment (500 $\mu \mathrm{g}$ terbutaline). A change in functional residual capacity after the bronchodilator of greater than $8 \%$ was accepted as clinically important. $^{3}$
To assess if $\alpha-1$ antitrypsin deficiency had a different effect on lung function than other hepatic diagnoses the functional residual capacity of the two groups were compared. To assess the effect of disease severity on lung function the results of the four subgroups were compared.

To assess if differences in functional residual capacity between the groups reached significance the Wilcoxon rank sum test was used.

\section{Results}

The children with $\alpha-1$ antitrypsin deficiency tended to have higher functional residual capacities related to both height $(\mathrm{p}<0.05)$ and age (non-significant) (mean $113 \%$, range $85-130 \%$ related to height and mean $104 \%$, range $67-128 \%$ related to age) than those suffering from other hepatic diagnoses (mean $100 \%, 78-106 \%$ related to height and mean $86 \%$, range $69-104 \%$ related to age). There was no significant difference in the children's height related to age between the two groups.

Only three children had significantly raised functional residual capacities $(>120 \%)$, all had $\alpha-1$ antitrypsin deficiency, but only one had severe liver disease (subgroup 2). Only one of the three showed a clinically important change in functional residual capacity after bronchodilator treatment; this child had previously been diagnosed as suffering from asthma. The other two, with functional residual capacities of $130 \%$ and $125 \%$ related to height, were 6.5 and 3.1 years old, respectively. Neither had chronic respiratory problems nor a positive family history. Both these children have subsequently been recalled and their functional residual capacities remain similarly raised.

Children with severe liver disease (subgroup 3 and some of subgroup 2) regardless of hepatic diagnosis tended to have lower functional residual capacities (see figure). All subgroup 3 had a functional residual capacity of less than $80 \%$ of that predicted for age, and this group had significantly lower lung volumes that the other three subgroups $(p<0 \cdot 01)$. Although one child of subgroup 3 was on the 10th centile for height, the other two were on the 50th and 90th centiles respectively.

\section{Discussion}

Owing to the difficulty, until recently, ${ }^{23}$ of performing respiratory function tests in young children, little has been known regarding the effect of hepatic disease and in particular $\alpha-1$ antitrypsin deficiency on lung function. In a small number of children (seven) less than 8 years of age, Vance et al showed both an abnormality of forced expiratory flow rate 
and increased frequency dependency of total pulmonary resistance measured by forced oscillation. ${ }^{4}$ There is only one reference to a younger child with $\alpha-1$ antitrypsin deficiency and respiratory disease. ${ }^{5}$ This child first presented at 8 years of age with a six and a half year history of chronic pulmonary disease, emphysema was diagnosed by lung biopsy at 13 years of age. In the present study three children, all with $\alpha-1$ antitrypsin deficiency, one as young as 3 years of age, had significantly raised lung volumes when related to both age and height. In two of these children this was unresponsive to bronchodilator treatment so these findings are highly suggestive of emphysematous changes. Neither child had severe liver disease, nor respiratory symptoms or signs.

In all children with severe liver disease, irrespective of diagnosis, low lung volumes were shown. This association was particularly noticeable when lung volumes were related to age. The children with severe liver disease, however, were not significantly smaller than the other children studied, indeed one was on the 90th centile for height. The most likely explanation, therefore, for the association of severe hepatic disease and reduced lung volume is compression due to hepatosplenomegaly and ascites.

In conclusion, these results suggest that $\alpha-1$ antitrypsin deficiency even in early childhood may be associated with emphysema, and that in severe liver disease lung volume is reduced. We now intend to follow all such children prospectively in an attempt to determine the exact incidence of respiratory abnormalities and their evolution with time.

Sister Jenny Pool is supported by Children Nationwide Medical Research Fund. Dr Colin Ball is supported by the Michael McGough Foundation against Liver Disease in Children. We thank Mrs Angela McPherson for secretarial help.

\section{References \\ Sveger T. Prospective study of children with alpha-1- antitrypsin deficiency: eight-year-old follow up. $J$ Pediatr 1984; 104:91-3. \\ 2 Greenough A, Stocks J, Nothen U, Helms P. Compliance and functional residual capacity in young children. Pediatr Pulmonol 1986;2:321-6. \\ ${ }^{3}$ Greenough A, Pool J, Loftus G, Price J. Abnormalities of lung mechanics in young asthmatic children. Thorax 1987;42:500-5. \\ + Vance JC, Hall NJ, Schwartz RH, Hyde RW, Roghmann KJ, Mudholkan GC. Heterozygous alpha-1-antitrypsin deficiency and respiratory function in children. Pediatrics 1977;60:263-72. \\ 5 Talamo RC, Levison H, Lynch MJ, et al. Symptomatic pulmon- ary emphysema in childhood associated with hereditary alpha-1-antitrypsin and elastase inhibitor deficiency. $J$ Pediatr 1971;79:20-6.}

Correspondence to Dr A Greenough, Department of Child Heath, King's College Hospital, Denmark Hill, London SE5 8RX.

Accepted 7 January 1988

\title{
Melatonin state in Mendenhall's syndrome
}

\author{
C D C RITTEY, T J EVANS, C E GRAY, R D PATON, AND C BOJKOWSKI
}

Royal Hospital for Sick Children, Yorkhill, Glasgow

SUMMARY We report a case of Mendenhall's syndrome that presented as hypoglycaemia. The clinical and biochemical features of the case are described including, for the first time, studies of melatonin state showing raised melatonin metabolite excretion in the urine as might be expected with disordered pineal function.

A syndrome of dysmorphism, dental precocity, hirsutism, acanthosis nigricans, abdominal protuberance, phallic enlargement, and insulin resistant diabetes mellitus was first described by Mendenhall in 1950.' Since then a number of similar cases have been recognised, ${ }^{2}$ and in each of these diabetes mellitus has developed in mid childhood and the child has died of ketoacidosis, with the exception of one child in whom hypophysectomy was performed. ${ }^{2}$ Pineal hyperplasia has been found at necropsy of all patients dying. ${ }^{1-3}$ We describe a further case in which the presenting symptom was hypoglycaemia in the neonatal period.

\section{Case report}

A boy, weighing $2520 \mathrm{~g}$, was born after an uneventful pregnancy at 44 weeks' gestation. It was the second pregnancy of healthy non-consanguinous parents. Abdominal distention and facial dysmorphism were noted at birth. The features included a coarse facies with a prominant jaw, large eyes and ears, fine downy hair over the body, and short stubby fingers. He was also noted to have a long penis with normal sized testes. At 10 hours of age the baby started to have seizures secondary to 